\title{
Estimation of Overhead Transmission Line Fault Distance Using Unsynchronized Two-Terminal Method
}

\author{
Ramadoni Syahputra*1, Indah Soesanti ${ }^{2}$ \\ ${ }^{1}$ Department of Electrical Engineering, Universitas Muhammadiyah Yogyakarta \\ Jl. Lingkar Selatan, Tamantirto, Kasihan, Yogyakarta, Indonesia \\ ${ }^{2}$ Department of Electrical Engineering and Information Technology, Faculty of Engineering, \\ Universitas Gadjah Mada \\ Jl. Grafika 2, Kampus UGM, Yogyakarta, Indonesia \\ *Corresponding author, e-mail: ramadoni@ugm.ac.id
}

\begin{abstract}
This paper presents the estimation of transmission line fault distance using unsynchronized two-terminal method. In operation, high or extra-high overhead voltage transmission lines can be interrupted. The disturbance can come from internal or external interference, which is permanent or temporary. For permanent interference, the network operator must visit the location of the disturbance in order to fix it. Because the transmission line is very long, while it takes quick time to find out the location of the disturbance so that it can be repaired immediately, then a method is needed to find out the location of the disturbance. This research proposes a method for determining the location of faults based on voltage and current data at the time of interference from both ends of the transmission line. The interference voltage and current data need not be synchronized. The use of this data makes this method very simple and easy to use. However, the accuracy of the estimation results can still be relied upon. In this study, a simulation was carried out on a two-end transmission line. The transmission line has a phase disturbance to the ground. The noise resistance applied in the simulation is 0 ohms, $10 \mathrm{ohms}, 50 \mathrm{ohms}$, and 100 ohms. The results showed that the highest estimated error was $0.3 \%$, which indicates that this method has a high degree of accuracy.
\end{abstract}

Keywords: Two-terminal fault location method, transmission line, unsynchronized sampling, Matlab software

\section{Introduction}

Transmission lines of any voltage level are subjects to faults. On the other hand, a continuous and reliable electrical energy supply is the objective of any power system operation. A transmission line is the part of the power system where faults are most likely to happen. Transmission line faults must be located accurately to allow maintenance crews to arrive at the scene and repair the faulted section as soon as possible. Rugged terrain and geographical layout make some sections of power transmission lines challenging to reach; therefore, the robustness of fault location determination under a variety of power system operating constraints and fault conditions is an essential requirement. To expedite repairs and fast restoration of power supply, it is essential to know where the fault is located. During the last few decades, progressive fault location schemes benefited from the development of digital techniques and microprocessor-based systems [1][3]. However, the accuracy of the distance to the fault determination is affected by several stochastic factors. Among the significant affecting factors, it could be mentioned the combined effect of the load, fault resistance, and equivalent impedances of the power systems connected to the ends of transmission line [4]-[5], as well as imprecision of the measurements and line parameters. Consequently, the accuracy of the fault location may be insufficient. 
Accurate location of faults on overhead power lines for the inspection-repair purpose is of vital importance for operators and utility staff for expediting service restoration, and thus to reduce outage time, operating costs and customer complains. During the last decade, several fault location algorithms have been developed, including the steady-state phasor approach, the differential equation approach, and the traveling-wave approach [6], as well as two-end [7] and one-end [8] algorithms. In the last category, synchronized [9] and non-synchronized [10] sampling techniques are used. However, two-terminal data are not widely available. In [11], the usage of synchronized measurements of currents and voltages from all two terminals has been considered. Distributed parameter models of the line sections have been utilized there. This condition assures high accuracy of fault location, and the faulted line section is also reliably indicated [11]. The use of three-end unsynchronized measurements of currents and voltages has been considered in [12]. The lumped models of the line sections were applied there, and it was also implied that the error resulting from such simplification is minimized due to the redundancy of the fault location equations. However, another utilization of three end unsynchronized measurements has been proposed in [13], where exchanging the minimal amount of information between the line terminals over a protection channel was considered. In turn, the demand and importance of developing fault location algorithms for three-terminal lines utilizing only two-end synchronized measurements of voltages and currents have been stated in [14]-[15]. From a practical viewpoint, equipment should use only oneterminal data. The one-end algorithms, in turn, utilize different assumptions to replace the remote end measurements. Most of the fault locators are only based on local measurements. Currently, the most widely used method of overhead line fault location is to determine the apparent reactance of the line during the time that the fault current is flowing and to convert the ohmic result into a distance based on the parameters of the line. It is widely recognized that this method is subject to errors when the fault resistance is high, and the line is fed from both ends, and when parallel circuits exist over only parts of the length of the faulty line.

In this paper, an algorithm, which utilizes unsynchronized measurements of currents and voltages at two-terminal of the transmission line is presented. The lumped parameter line model is strictly utilized. The method utilizes the advantages of digital technology and numerical relaying, which are available today. The method allows for accurate estimation of fault location irrespective of fault types, fault resistance, load currents, and source impedances.

\section{Faults in Transmission Line}

Faults in power systems are generally classified as short circuits (shunt faults) and interruptions (series faults) [16]. Both types can be balanced or unbalanced. Unbalanced faults cause an imbalance at the fault location between the phases of the power system, which is usually assumed to be balanced. Faults can occur as single faults of simultaneous faults. Most of the faults in transmission lines are a single line to ground type. Hence, the type of fault is used in this study.

Simultaneous faults consist of a combination of the same or different types of faults. The preferred model for fault calculation is the nodal approach in the frequency domain with symmetrical components or in the time domain with space phasors or its components [17]. The conventional calculation methods, based on equations in admittance form, lead to numerical problems if the fault impedances become zero. Another general problem is the treatment of simultaneous faults. Each fault is characterized by the so-called boundary conditions (BC) regarding the voltages and currents at the fault location [18].

In an electric power system comprising of different complex interacting elements, there always exists a possibility of disturbance and fault. The advent of large generating stations and highly interconnected power systems makes early fault detection and rapid equipment isolation imperative to maintain system stability [19]. Faults on power system transmission lines need to be detected and located rapidly, classified correctly, and cleared as fast as possible. The fault detector module of a transmission line protective scheme can be used to start other relaying modules. Fault detectors provide an additional level of security in a relaying application as well, and the location of the fault must be estimated.

Besides being used to locate a fault accurately, such an algorithm can be used for automated fault analysis. Any occurrence of a fault should be detected and cleared by the protective relaying devices. An analysis of the protective relaying operation is required if an assessment of its performance is needed. In order to perform the 
analysis, one has to have a reference algorithm with which to compare the relay operation. The fault location algorithm that can provide both fault classification and location is an ideal reference for the correct protective relaying operation. The algorithm can be incorporated into an automated fault analysis by providing a high-speed indication of the fault type and fault location [20]. This fact is sufficient information for determining if a protective relay has operated correctly since the relay is also supposed to determine fault type and location. Location determined by the relay does not have to be too accurate since it only has to determine the zone of the fault occurrence. The exact location of the fault provided by the fault location algorithm is more accurate and is needed as a comparison reference point.

\section{Methodology}

The method of estimation of short circuit fault location in this research is to use two terminals approach for two ends electrical power transmission line, as shown in figure 1 [10].

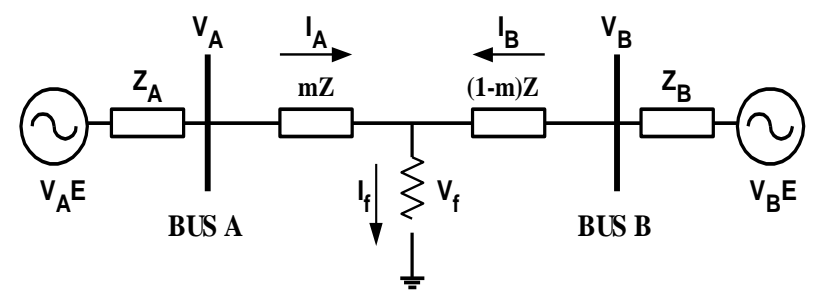

Figure 1. Short circuit faulted transmission lines.

For the transmission line given in Figure 1, the following two phasors, voltage, and current, from protected two-terminal transmission lines are required in this method, but unsynchronized. A phasor is a complex number that represents the fundamental frequency component of a waveform. As can be seen in figure 1, the method will estimate fault distance $m$ from two ends of the overhead transmission line.

The data of voltage and current at bus A and bus B are not synchronized, and angle synchronization between related phasors is d. For example, the voltage at bus A and bus B can be written as follow:

$$
V_{A}=\left|V_{A}\right| \angle \alpha_{m}+\delta ; \quad V_{B}=\left|V_{B}\right| \angle \beta_{m}
$$

Where $\alpha_{m}$ and $\beta_{m}$ are measured angle from two ends, respectively. Then, $\delta$ is the angles which needed to synchronize the phasor at bus A regard to bus B. The similar equation can write for current. Hence, equation (1) has become:

$$
V_{A} e^{j \delta}-V_{B}+Z I_{B}=m Z\left(I_{A} e^{j \delta}+I_{B}\right)
$$

The unknown component at equation (2) are distance fault $\mathrm{m}$ and complex number $\delta=\mathrm{e}^{\mathrm{j} \delta}$. Equation (2) can be separated to two parts, real and imaginer, to forms the new two equations as follow:

$$
\begin{gathered}
\operatorname{Re}\left(V_{A}\right) \sin \delta+\operatorname{Im}\left(V_{A}\right) \cos \delta-\operatorname{Im}\left(V_{B}\right)+K_{4} \\
=m\left(K_{l} \sin \delta+K_{2} \cos \delta+K_{4}\right) \\
\operatorname{Re}\left(V_{A}\right) \cos \delta-\operatorname{Im}\left(V_{A}\right) \sin \delta-\operatorname{Re}\left(V_{B}\right)+K_{3} \\
=m\left(K_{l} \cos \delta-K_{2} \sin \delta+K_{3}\right)
\end{gathered}
$$

Coefficients of $K_{1}, K_{2}, K_{3}$, and $K_{4}$ in equation (3) and equation (4) can be defined as follow:

$$
\begin{aligned}
& K_{l}=R \operatorname{Re}\left(I_{A}\right)-X \operatorname{Im}\left(I_{A}\right) \\
& K_{2}=R \operatorname{Im}\left(I_{A}\right)+X \operatorname{Re}\left(I_{A}\right) \\
& K_{3}=R \operatorname{Re}\left(I_{B}\right)-X \operatorname{Im}\left(I_{B}\right) \\
& K_{4}=R \operatorname{Im}\left(I_{B}\right)+X \operatorname{Re}\left(I_{B}\right)
\end{aligned}
$$

Then, the equation with unknown angle $\delta$ is formed. As rearranged the equations above, then the new equations are resulted as follow:

$$
a \sin \delta+b \cos \delta+c=0
$$

where,

$$
\begin{aligned}
& a=-K_{3} \operatorname{Re}\left(V_{A}\right)-K_{4} \operatorname{Im}\left(V_{A}\right)-K_{I} \operatorname{Re}\left(V_{B}\right) \\
& -K_{2} \operatorname{Im}\left(V_{B}\right)+K_{1} K_{3}+K_{2} K_{4} \\
& b=K_{4} \operatorname{Re}\left(V_{A}\right)-K_{3} \operatorname{Im}\left(V_{A}\right)-K_{2} \operatorname{Re}\left(V_{B}\right) \\
& +K_{l} \operatorname{Im}\left(V_{B}\right)+K_{2} K_{3}-K_{1} K_{4} \\
& c=K_{2} \operatorname{Re}\left(V_{A}\right)-K_{I} \operatorname{Im}\left(V_{A}\right)-K_{4} \operatorname{Re}\left(V_{B}\right)+K_{3} \operatorname{Im}\left(V_{B}\right)
\end{aligned}
$$

From equation (11) can be seen that angle $\delta$ (synchronization angle) is unknown. The unknown one can be found using the Newton-Raphson iterative method. The equation for iteratively to count the angle $\delta$ (in radian) is:

$$
\delta_{k+1}=\delta_{k}-\frac{F\left(\delta_{k}\right)}{F^{\prime}\left(\delta_{k}\right)}
$$

The iterative process will stop if the difference between the two end values is smaller than the stated float, for example: $\delta_{k+1}-\delta_{k}<10^{-4}$. The method has the quadrate convergence and needs initial value. If the voltage angle of two terminals of transmission line is zero respectively, then angle $\delta$ be an apparent angle between two voltages and independent to synchronization error. As the synchronization has known, fault distance from one of two ends of line can be accounted from equation (3) and equation (4). From equation (3):

$$
m=\frac{\operatorname{Re}\left(V_{A}\right) \sin \delta+\operatorname{Im}\left(V_{A}\right) \cos \delta-\operatorname{Im}\left(V_{B}\right)+K_{4}}{K_{1} \sin \delta+K_{2} \cos \delta+K_{4}}
$$


If we use equation (4), then fault distance $m$ can be accounted as follow:

$$
m=\frac{\operatorname{Re}\left(V_{A}\right) \cos \delta-\operatorname{Im}\left(V_{A}\right) \sin \delta-\operatorname{Re}\left(V_{B}\right)+K_{3}}{K_{1} \cos \delta-K_{2} \sin \delta+K_{3}}
$$

Equation (14) and (15) can be used to all of the short circuit fault types. This method can apply to an overhead transmission line with multi-phase cases. The amount of appropriate phase can be used in this method.

And, error estimation is calculated by the equation below [18]:

$$
\text { Error }(\%)=\frac{\mid \text { actual location }- \text { estimated lokation } \mid}{\text { line length }} \times 100 \%(16)
$$

Based on this estimation error calculation, information about the accuracy of the method used in this study will be obtained.

\section{Results and Discussion}

For evaluating the performance of the proposed algorithm, the author adopts EDSA software for fault data generation and Matlab for algorithm implementation. The power system shown in Figure 1 was selected for the studies reported in this paper. Bus $\mathrm{A}$ and bus B were considered to be connected by $150 \mathrm{~km}, 500 \mathrm{kV}$ transmission lines [18]-[20]. Two equivalent power systems considered to be connected to bus A and bus B. Electrical parameters of transmission lines and equivalent power sources are given in Table 1.

TABLE I

ELECTRICAL PARAMETERS OF TRANSMISSION LINE IN THIS STUDY

\begin{tabular}{l|c|c|c}
\hline \multirow{2}{*}{ Components } & \multicolumn{3}{|c}{ Impedances } \\
\cline { 2 - 4 } & $\begin{array}{c}\text { Positive sequence } \\
\left(\mathrm{Z}_{1}\right)\end{array}$ & $\begin{array}{c}\text { Negative sequence } \\
\left(\mathrm{Z}_{2}\right)\end{array}$ & $\begin{array}{c}\text { Zero sequence } \\
\left(\mathrm{Z}_{0}\right)\end{array}$ \\
\hline Transmission lines & $53,090 \angle 86,07^{\circ}$ & $53,090 \angle 86,07^{\circ}$ & $173,683 \angle 72,96^{\circ}$ \\
\hline Power source A & $4,001 \angle 89,03^{\circ}$ & $3,501 \angle 88,90^{\circ}$ & $1,414 \angle 45^{\circ}$ \\
\hline Power source B & $100,020 \angle 88,85^{\circ}$ & $75,027 \angle 88,47^{\circ}$ & $25,072 \angle 85,65^{\circ}$ \\
\hline
\end{tabular}

TABLE II

Fault Distance Estimation for Single Phase-to-Ground Fault

\begin{tabular}{c|c|c|c|c}
\hline \multirow{2}{*}{$\begin{array}{c}\text { Actual Distance } \\
(\mathrm{km})\end{array}$} & $\mathrm{R}_{\mathrm{f}}=0 \Omega$ & $\mathrm{R}_{\mathrm{f}}=10 \Omega$ & $\mathrm{R}_{\mathrm{f}}=50 \Omega$ & $\mathrm{R}_{\mathrm{f}}=100 \Omega$ \\
\cline { 2 - 5 } & 0,0027183 & 0,0024771 & 0,0093352 & 0,0170958 \\
\hline 0 & 0,0125956 & 0,0033028 & 0,0119279 & 0,0219511 \\
\hline 15 & 0,0090500 & 0,0080960 & 0,0221115 & 0,0390903 \\
\hline 30 & 0,0195715 & 0,0163435 & 0,0358773 & 0,0600260 \\
\hline 45 & 0,0211366 & 0,0280220 & 0,0532048 & 0,0847273 \\
\hline 60 & 0,0227297 & 0,0431110 & 0,0740820 & 0,1131887 \\
\hline 75 & 0,0243211 & 0,0615933 & 0,0985028 & 0,1454183 \\
\hline 90 & 0,0258992 & 0,0834552 & 0,1264669 & 0,1814347 \\
\hline 105 & 0,0274970 & 0,1086872 & 0,1579806 & 0,2212671 \\
\hline 120 & 0,0291193 & 0,1372857 & 0,1930578 & 0,2649561 \\
\hline 135 & 0,0307341 & 0,1582224 & 0,2184332 & 0,2962510 \\
\hline 150 & & & & \\
\hline
\end{tabular}

For pre-fault calculations, all transmission lines were modeled by equivalent pi networks, and all loads were considered to be constant power loads. For calculating fault currents and voltages on the inception of a fault, the selected line was modeled by two equivalent pi networks, one for the section from bus $A$ to the fault and the other for the section from bus $\mathrm{B}$ to the fault. For testing the fault distance technique, it was assumed that digital impedance relays have been provided at the line terminals on bus 
$\mathrm{A}$ and bus B. It was also assumed that this distance relays measure fundamental frequency voltages and currents from sampled data.

In this research, a single-phase to ground fault was applied to the selected location of the transmission line. Buses A and B and some locations, i.e., $15 \mathrm{~km}$, $30 \mathrm{~km}, 45 \mathrm{~km}, 60 \mathrm{~km}, 75 \mathrm{~km}, 90 \mathrm{~km}, 105 \mathrm{~km}, 120$ $\mathrm{km}$, and $135 \mathrm{~km}$, were chosen as fault locations. Fault resistances were varied from $0,10,50$, to $100 \mathrm{ohms}$. Fundamental frequency voltages at bus A and bus B and line currents were calculated and were provided to the fault location program in MATLAB as inputs. Fault location studies for single-phase to ground faults are reported in this paper, as shown in Table II and Figure 2.
Table II lists the error estimated fault locations for a single-phase to ground fault with fault resistances of $0,10,50$, and $100 \mathrm{ohms}$, respectively. The estimation errors expressed as percentages of the line length are shown in Figure 2. The results indicate that distances of faults estimated by the proposed method are substantially more accurate than the distances estimated by Sachdev and Agarwal [18]. When a single-phase to ground fault occurs in bus A $(0 \mathrm{~km}$ distance) with fault resistance of $0 \mathrm{ohms}$, the estimation error is $0.0027183 \%$. This error value is the smallest estimation error in the study. As can be seen in Table II and Figure 2 that the excellent estimation error for a single-phase to ground fault is $0.2962510 \%$ at $150 \mathrm{~km}$ distance with fault resistance of $100 \mathrm{ohms}$.

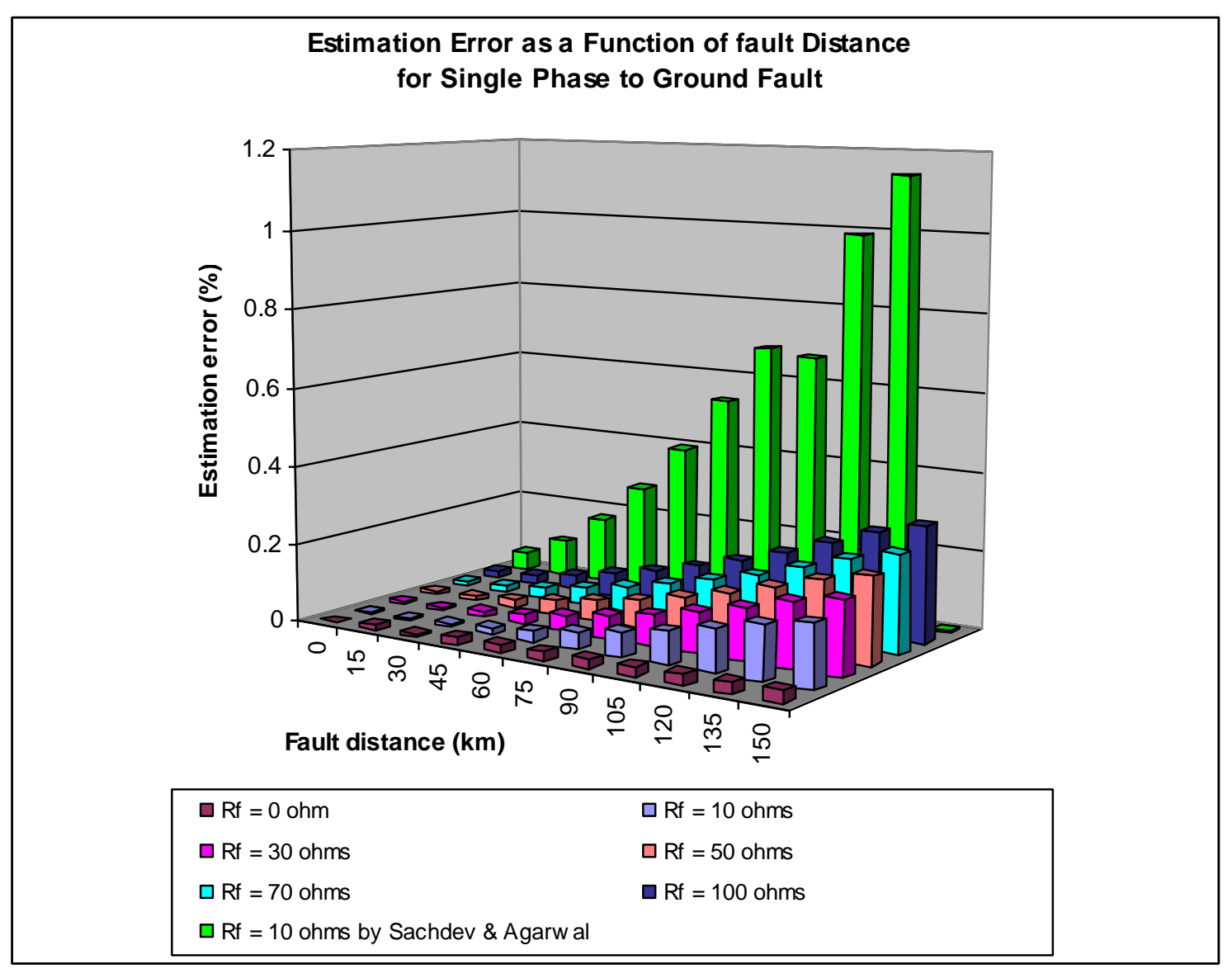

Figure 2. Estimation error as a function of fault distance for single phase to ground fault.

\section{Conclusion}

This paper has described a technique that estimates the distance of a transmission line short circuit fault from relay locations using unsynchronized fundamental frequency voltages and currents measured at the line terminals. The method utilizes the advantages of digital technology and numerical relaying, which are available today. The method allows for accurate estimation of fault location irrespective of fault types, load currents, and source impedances. From the simulation, it is obtained that 
the significant estimation error for single-phase to ground fault with the variation of fault resistances of $0 \mathrm{ohms}, 10 \mathrm{ohms}, 50 \mathrm{ohms}$, and $100 \mathrm{ohms}$ is $0.3 \%$ at $150 \mathrm{~km}$ distance. The proposed technique is simple, accurate, and unsynchronized data. It can be implemented as a part of the post fault analysis package for microprocessor-based digital impedance relay.

\section{References}

[1] T. Takagi, Y. Yamakoshi, M. Yamuaura, R. Kondow, and T. Matsushima, "Development of a New Type of Fault Locator Using One Terminal Voltage and Current Data", IEEE Trans. On Power Apparatus and System, vol. PAS-101, No 8, pp. 2892-2898, Aug. 1982.

[2] L. Eriksson, M. Saha, and S.D. Rockfeller, "An Accurate Fault Location with Compensation for Apparent Reactance in the Fault Resistance Resulting from Remote-end in feed", IEEE Trans. on PAS, PAS-104, No 2, 1985

[3] D. Novosel, D.G. Hart, M.M. Saha, and S. Gress, "Optimal fault location for transmission system", ABB Review 8, pp. 20-27, 1994.

[4] Syahputra, R., Robandi, I., Ashari, M. (2015). Performance Improvement of Radial Distribution Network with Distributed Generation Integration Using Extended Particle Swarm Optimization Algorithm. International Review of Electrical Engineering (IREE), 10(2). pp. 293-304.

[5] A. Sauhats and M. Bockarjova, "Algorithms, Means and Tools of Fault Location on Transmission Lines", Proc. EPE-PEMC'2004, Riga, Latvia, 2004.

[6] B. Lian and M.M.A. Salama, "An overview of digital fault location algorithms for power transmission lines using transient waveforms", Electric Power Syst. Res.., Vol. 29, No. 1, pp. 17-25, 1994.

[7] L.B. Sheng and S. Elangovan, "A fault location algorithm for transmission lines", Electric Machines \& Power Syst., Vol. 26, No. 10, pp. 991-1005, 1998.

[8] Q. Zhang, Y. Zhang, W. Song, and Y. Yu, "Transmission line fault location for phase-to-earth fault using oneterminal data", IEE Proc. Trans. Distribution., Vol. 146, No. 2, pp. 121-124, 1999.

[9] M. Kezunovic, and J. Mrkic, "An accurate fault location algorithm using synchronized sampling", Electric Power Syst. Res., Vol. 29, No. 3, pp. 161169, 1994.

[10] D. Novosel, D.G. Hart, E. Udren, and J. Garitty, "Unsynchronized two-terminal fault location estimation", IEEE Trans. Power Delivery, Vol. 11, No. 1, pp. 130-138, 1996.

[11] R.K. Aggarwal, D.V. Coury, A.T. Johns, and A. Kalam, "A practical approach to accurate fault location on extra high voltage teed feeders", IEEE Trans. Power Delivery, Vol. 8, pp. 874-883, July 1993.
[12] A.A. Girgis, D.G. Hart, and W.L. Peterson, "A new fault location technique for two-and three-terminal lines", IEEE Trans. Power Delivery, Vol. 7, No.1, pp. 98-107, January 1992.

[13] D. A. Tziouvaras, J. Roberts and G. Benmmouyal, "New multi-ended fault location design for two- or three-terminal lines", Proceedings of 7th International IEE Conference on Developments in Power System Protection, pp. 395-398, April 2001.

[14] Y. Lin, C. Liu, and C. Yu, "A new fault locator for three-terminal transmission lines using two-terminal synchronized voltage and current phasors", IEEE Trans. Power Delivery, Vol. 7, No.3, pp. 452-459, July 2002.

[15] S.M. Brahma, "Fault Location Scheme for a MultiTerminal Transmission Line Using Synchronized Voltage Measurements", IEEE Trans. on Power Delivery, Vol. 20, No. 2, pp. 1325-1331, April 2005.

[16] B. R. Oswald and A. Panosyan, "A New Method for the Computation of Faults on Transmission Lines", IEEE PES Transmission and Distribution Conference and Exposition Latin America, Venezuela, 2006.

[17] J. Izykowski, E. Rosolowski, M.M. Saha, M. Fulczyk and P. Balcerek, "A fault location method for application with current differential relays of three terminal lines", IEEE Trans. on Power Delivery, Vol. 22, No. 4, pp. 2099-2107, October 2007.

[18] M.S. Sachdev and R. Agarwal., "A Technique for Estimating Transmission Line Fault Locations from Digital Impedance Relay Measurements", IEEE Trans. on PWRD, 3(1), 121-129, 1988.

[19] Syahputra, R., Soesanti, I. (2016). An Optimal Tuning of PSS Using AIS Algorithm for Damping Oscillation of Multi-machine Power System. Journal of Theoretical and Applied Information Technology (JATIT), 94(2), pp. 312-326.

[20] Syahputra, R. (2017). Distribution Network Optimization Based on Genetic Algorithm. Jurnal Teknologi, Journal of Electrical Technology UMY (JET-UMY), 1(1), pp. 1-9.

\section{Authors' information}

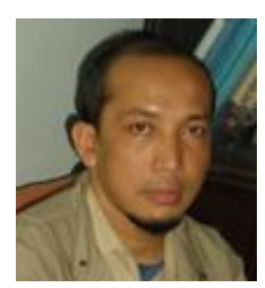

Ramadoni Syahputra received B.Sc. degree from Institut Teknologi Medan in 1998, M.Eng. degree from Department of Electrical Engineering, Universitas Gadjah Mada, Yogyakarta, Indonesia in 2002, and Ph.D degree at the Department of Electrical Engineering, Faculty of Industrial Technology, Institut Teknologi Sepuluh Nopember, Surabaya, Indonesia in 2015.

Dr. Ramadoni Syahputra is a Lecturer in Department of Electrical Engineering, Faculty of Engineering, Universitas Muhammadiyah Yogyakarta, Indonesia. His research interests are in computational of power system, artificial intelligence in power system, power system control, the application of fuzzy 
logic in power system, optimization, distributed energy resources, and renewable energy.

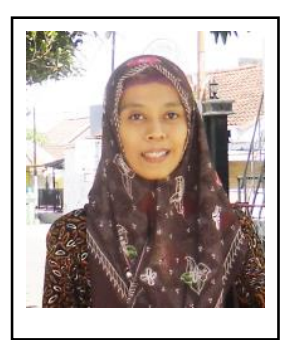

Indah Soesanti was born on June 15, 1974. She received both M.Eng. and Ph.D. degrees from Department of Electrical Engineering, Gadjah Mada University, Yogyakarta, Indonesia in 2001 and 2011, respectively.

Dr. Indah Soesanti is a Lecturer in the Department of Electrical Engineering and Information Technology, Faculty of Engineering, Universitas Gadjah Mada, Indonesia. Her research interests are in signal processing, image processing, control system, ICT-based system, optimization, artificial intelligence in signal processing pattern classification, and artificial intelligence in control system. 